\title{
Associations Between Season, Processing Plant, and Hide Cleanliness Scores with Prevalence and Concentration of Major Shiga Toxin-Producing Escherichia coli on Beef Cattle Hides
}

\author{
Natalia Cernicchiaro, ${ }^{1,2}$ Ana R.S. Oliveira, ${ }^{2}$ Allison Hoehn, ${ }^{2, *}$ Lance W. Noll, ${ }^{2}$ Pragathi B. Shridhar, \\ Tiruvoor G. Nagaraja, ${ }^{2}$ Samuel E. Ives, ${ }^{3, \dagger}$ David G. Renter, ${ }^{1,2}$ and Michael W. Sanderson ${ }^{1,2}$
}

\begin{abstract}
The objectives of this study were (1) to estimate the prevalence and concentration of the seven major Shiga toxin-producing Escherichia coli (STEC) serogroups (O26, O45, O103, O111, O121, O145, and O157), collectively called STEC-7, on cattle hides collected in different seasons and beef processing plants; and (2) to determine associations of season, plant, and hide cleanliness scores with the prevalence and concentration of STEC-7. A total of 720 hide surface samples (240/season) were collected over three seasons (summer and fall 2015 and spring 2016) from beef cattle carcasses in four commercial processing plants in the United States. Samples were subjected to selective culture and spiral plating methods. Overall model-adjusted mean prevalence $(95 \%$ confidence interval) was $0.3 \%(0.03-2.3 \%)$ for STEC O26; $0.05 \%(<0.01-8.5 \%)$ for STEC O45; $0.2 \%(0.02-1.9 \%)$ for STEC O103; $0.05 \%(<0.01-8.5 \%)$ for STEC O145; and 3.1\% (0.6-15.2\%) for STEC O157. Four percent of hide samples were enumerable for STEC O157; mean concentration (standard deviation $)=2.1(0.7) \log _{10}$ colony-forming units $(\mathrm{CFUs}) / 100 \mathrm{~cm}^{2}$. No samples were enumerable for non-O157 STEC. Hide-on prevalence of STEC O157 and STEC non-O157 (specifically of STEC O103) was higher in summer and spring, respectively. Across seasons and plants, the most common STEC non-O157 serogroups in this study (O26 and O103) were associated with a higher prevalence of STEC O157. Season and plant played a role in prevalence and concentration of STEC in beef cattle hides, varying by serogroup. Tailoring mitigation strategies at the plant can be challenging and processors would benefit from supplementary preharvest interventions to reduce overall contamination pressure at the plant, especially in fall and spring months when hide-on prevalence of STEC non-O157 is higher.
\end{abstract}

Keywords: beef cattle, hides, prevalence, risk factors, Shiga toxin-producing Escherichia coli

\section{Introduction}

$\mathbf{S}$ EVERAL SEROGROUPS OF Shiga toxin-producing Escherichia coli (STEC) have been associated with outbreaks of human illness, with E. coli $\mathrm{O} 157$ being the serogroup most frequently isolated in North America (Brooks et al., 2005). Conversely, serogroups O26, O45, O103, O111, O121, and O145 were reported to account for $71 \%$ of all non-O157 STEC human enteric infections occurring between 1983 and 2002 in the United States (Scallan et al., 2011). Given the increase in cases of human illnesses associated with the six non-O157 serogroups, the U.S. Department of Agriculture's Food Safety and Inspection Service (USDA-FSIS) declared them adulterants of raw beef and nonintact products in 2012 (USDA-FSIS, 2012).

Cattle are the major natural reservoir of STEC, both O157 and non-O157 (Bettelheim, 2000). After bacterial colonization of their lower gastrointestinal tract, cattle shed STEC in their feces (Caprioli et al., 2005; Pennington, 2010). At slaughter plants, fecal contamination of hides can occur while

\footnotetext{
${ }^{1}$ Center for Outcomes Research and Epidemiology, College of Veterinary Medicine, Kansas State University, Manhattan, Kansas, USA.

${ }^{2}$ Department of Diagnostic Medicine and Pathobiology, College of Veterinary Medicine, Kansas State University, Manhattan, Kansas, USA.

${ }^{3}$ Department of Agricultural Sciences, College of Agriculture and Natural Sciences, West Texas A\&M University, Canyon, Texas, USA.

* Current affiliation: Merck Animal Health, De Soto, Kansas, USA.

${ }^{\dagger}$ Current affiliation: Ceva Animal Health, Ltd., Lenexa, Kansas, USA.
} 
cattle are in lairage pens, during dehiding, and during carcass processing through cross-contamination with equipment, viscera, or utensils (Elder et al., 2000; Arthur et al., 2004; Bosilevac et al., 2005; Ekong et al., 2015).

Processing plants implement numerous interventions to reduce contamination and transfer of STEC from cattle hides to carcasses and beef products (Wheeler et al., 2014). The USDA-FSIS encourages the use of a mud scoring system to quantify the amount of mud on cattle upon arrival and identify animals that may pose an increased risk of contamination during hide removal. Processing plants may use that information to decrease the speed of the line, add trimmers, or modify other processes (USDA-FSIS, 2017). Other early interventions may consist of applying bacteriophages to reduce STEC in lairage pens and hide water washes to decrease contamination with large particles, mud, and dust as cattle enter the processing plant. Microbiological testing of hides can also be implemented to determine the bacterial load of incoming cattle, and several other best practices are recommended during hide removal, especially regarding mechanical dehiding (USDA-FSIS, 2017).

Although there is evidence pointing to hides as an important source of carcass contamination, most of those studies pertain to STEC O157. Data regarding prevalence and concentration of STEC non-O157 serogroups on hides to assess the bacterial load of beef cattle upon arrival at the processing plant and the impact of season, plant, and mud scores on prevalence are still limited or inconsistent (Ekong et al., 2015; Stromberg et al., 2015; Schneider et al., 2018). Therefore, the objectives of this study were (1) to determine the prevalence and concentration of the seven major STEC serogroups (O26, O45, O103, O111, O121, O145, and O157) on hides of beef cattle carcasses collected from four Midwestern commercial beef processing plants in different seasons; and (2) to determine associations of season, processing plant, and hide cleanliness scores (mud scoring) with the prevalence and concentration of STEC on hides.

\section{Materials and Methods}

\section{Sample collection and processing}

Samples were collected from four large, commercial processing plants located in the states of Kansas, Nebraska, and Texas in the United States. Each plant was visited three times during summer (June/July 2015), fall (October/November 2015), and spring (March/April 2016) seasons.

Plants processed between 340 and 490 cattle per hour, and the source population consisted of adult fed beef cattle procured from Midwest feedlot operations (the majority being European crosses). The study sample consisted of 20 hide samples collected per visit, per plant, and per season. One hide from every ten (given the speed of carcass processing) individual beef cattle carcasses was collected, immediately postexsanguination and before hide wash and/or removal, at routine plants' chain speeds and during normal operating hours.

The hide sampling area consisted of $2730 \mathrm{~cm}^{2}(30 \times$ $91 \mathrm{~cm}), \sim 15 \mathrm{~cm}$ from the midline and from the elbow line to the umbilicus area (brisket to flank) (modified from USDAFSIS, 2005; Noll et al., 2018; Cernicchiaro et al., 2019)



FIG. 1. Diagram depicting hide sampling area. (Picture by Dr. Natalia Cernicchiaro, diagram courtesy of Mrs. Mal Hoover, Illustrator, College of Veterinary Medicine, Kansas State University.) Color images are available online.

(Fig. 1). Before hide sampling and immediately after carcass exsanguination, a member of the research team assigned beef cattle hides a contamination score of 0,1 , or 2 based on the presence of feces and/or mud on the ventral and lateral sides of the abdomen, from the brisket to the umbilicus, as follows: 0 if $<10 \%$ of the sampling area was covered with feces or mud; 1 if $10-30 \%$ of the sampling area was covered; and 2 if $>30 \%$ of the sampling area was covered with feces or mud (modified from Hauge et al., 2012). Sampling was done with Whirl-Pak $^{\circledR}$ Speci-Sponges (Nasco, Fort Atkinson, WI) saturated in $35 \mathrm{~mL}$ of Butterfield's buffer (Hardy Diagnostics, Santa Maria, CA) with $0.1 \%$ Tween 20 (Fisher Scientific, Pittsburg, PA). Samples were collected by applying 10 twodirectional strokes (five strokes per sponge side) up and down or side to side. After sample collection, the sponge was placed into the Whirl-Pak bag and its contents were manually mixed five times (modified from the study by Arthur et al., 2004). 
Samples were refrigerated immediately after collection (placed in coolers with ice packs) and then transported to the Pre-Harvest Food Safety Laboratory at the College of Veterinary Medicine, Kansas State University, where they were kept refrigerated at $4^{\circ} \mathrm{C}$ until being processed within $24 \mathrm{~h}$.

After homogenizing the content of the Whirl-Pak bags, sponges were discarded, and the liquid was removed using a 50-mL transfer pipette. A $10-\mathrm{mL}$ aliquot of each sample was returned to the Whirl-Pak bags for enrichment, and the remaining liquid (approximately $18-19 \mathrm{~mL}$ ) was transferred to sterile test tubes for spiral plating.

\section{Culture-based method for detection of STEC}

For enrichment, $90 \mathrm{~mL}$ of E. coli broth (Oxoid Ltd., Hampshire, United Kingdom) was added to each Whirl-Pak bag (containing $10 \mathrm{~mL}$ of sample), then squeezed and incubated at $40^{\circ} \mathrm{C}$ for $6 \mathrm{~h}$. Postenriched samples were subjected to immunomagnetic separation (IMS) using a Kingfisher ${ }^{\mathrm{TM}}$ Flex Magnetic Particle Processor (Thermo Scientific, Waltham, MA): IMS beads for O157 (Abraxis, Warminster, PA); pooled IMS beads for O26, O45, and O111; and pooled IMS beads for O103, O121, and O145 IMS (Noll et al., 2016). For the O157 IMS treatment, $20 \mu \mathrm{L}$ of O157 IMS beads and $980 \mu \mathrm{L}$ of enriched sample were added to a well of a 96-well plate. For the pooled IMS beads, $20 \mu \mathrm{L}$ of each individual IMS bead and $940 \mu \mathrm{L}$ of the enriched sample were added to a well of a 96-well plate. After the IMS treatment, $25 \mu \mathrm{L}$ of bead suspension was spread plated onto sorbitol-MacConkey agar supplemented with cefixime $(0.5 \mathrm{mg} / \mathrm{L})$ and potassium tellurite $(2.5 \mathrm{mg} / \mathrm{L}$; CT-SMAC; for 0157) or a modified Possé (MP) agar plate (for nonO157 serogroups) (Noll et al., 2015). Plates were incubated at $37^{\circ} \mathrm{C}$ for $20-24 \mathrm{~h}$.

Ten chromogenic colonies from MP agar plates were selected, streaked onto blood agar plates, and incubated at $37^{\circ} \mathrm{C}$ for 20-24 h. Isolates were then pooled and subjected to a 10plex polymerase chain reaction (PCR) assay, targeting genes for the major serogroups and three major virulence genes, stx 1, stx2, and eae, for STEC confirmation (Bai et al., 2012). Six nonsorbitol-fermenting colonies from CT-SMAC plates were selected, streaked onto blood agar plates, and incubated at $37^{\circ} \mathrm{C}$ for $20-24 \mathrm{~h}$. Isolates were tested for $\mathrm{O} 157$ confirmation by latex agglutination, indole production, and a sixplex PCR (Bai et al., 2010).

\section{Spiral plating for quantification of STEC}

One milliliter of each sample (pre-enrichment) was transferred to a microcentrifuge tube for spiral plating. One hundred microliters were spiral plated (Eddy Jet Spiral Plater; IUL Instruments, Barcelona, Spain) onto an MP agar plate for non-O157 STEC enumeration. Another $100-\mu \mathrm{L}$ aliquot was spiral plated onto CT-SMAC for STEC O157 enumeration. Plates were incubated at $37^{\circ} \mathrm{C}$ for $20-24 \mathrm{~h}$ and then enumerated using a counting grid that relates colony counts to sample volume deposited in the area (Gilchrist et al., 1973; Shridhar et al., 2017), with the range of detection limit being $2 \times 10^{2}-4 \times 10^{5}$ colony-forming units (CFUs)/ $\mathrm{mL}$ (IUL, S.A., 2012) (Eddy Jet 2 User's Guide V. 1.0., Barcelona, Spain). Verification of STEC was performed by PCR methods, as described in the previous section.

\section{Statistical analyses}

All statistical analyses were performed in Stata 12 (StataCorp LP, College Station, TX). A sample was considered STEC positive if for a specific O serogroup, st $x 1$ and/or $s t x 2$ virulence genes were detected in at least one sample isolate by culture methods. The percent of positive samples consisted of the number of hide-on samples that tested positive for each of the seven STEC serogroups by culture methods divided by the total number of samples collected per season and per plant. Mean, median, standard deviation, and minimum and maximum concentration of STEC colonies on enumerable plates (plates with at least one visible colony) from hide samples, in $\log _{10} \mathrm{CFU} / 100 \mathrm{~cm}^{2}$, were summarized per study season and per plant. Distribution of hide cleanliness scores by STEC $O$ group, season, and processing plant is presented in frequency tables.

Associations between risk factors of interest (season, plant, and hide cleanliness score) and the prevalence of STEC-7 serogroups were estimated using multilevel, mixed-effect logistic regression models with a binary distribution, logit link, and adaptive quadrature estimation (xtmelogit command in Stata 12). Dependent variables consisted of test results at the sample level for each STEC O group (modeled as presence/absence [1/0]). Separate models were run for each of the seven STEC serogroups if the effective sample size allowed it. Independent variables tested included season (modeled as a categorical variable: summer, fall, and spring), processing plant (categorical: plants 1-4), and hide cleanliness score (categorical: 0-2). Two types of models were built: (1) Univariable models: to determine associations of season and plant as fixed effects, in separate models, with the prevalence of each STEC O serogroup. To account for the hierarchical structure of the study, random intercepts for pen and sampling week were incorporated, except when plant was evaluated as a fixed effect (in that case, sampling week was incorporated as the random intercept). (2) Multivariable models: to determine associations of hide cleanliness scores with hide-on prevalence of STEC O157 after accounting for season as a confounding variable. This model included the prevalence of STEC O157 as an outcome, hide scores and season as fixed effects, and random intercepts for plant and week of sampling. Due to the small, effective sample size, only univariable models were fitted for STEC O26 and O103 prevalence outcomes ( $n=12$ and 21, respectively) and only main effects, but no interaction terms, were fitted in the multivariable model for STEC O157.

Unconditional associations of season, plant, and hide cleanliness scores with the concentration of STEC O157 (in $\log _{10} \mathrm{CFU} / 100 \mathrm{~cm}^{2}$ ) were evaluated using multilevel, mixed-effect linear regression models with a Gaussian distribution, identity link, and restricted maximum likelihood (xtmixed command in Stata 12). Models were built as described above.

Residual diagnostics consisted of the graphical evaluation of the distribution of the best, linear unbiased prediction for the plant and sampling week random intercepts. In addition, standardized and delta deviance residuals at the sample level were graphically evaluated to identify potential outlier and influential observations. Associations were considered statistically significant at $p<0.05$. Model-adjusted mean prevalence, or mean concentrations, and their $95 \%$ confidence 
Table 1. Number and Percent of Test-Positive

Cattle Hide Surface Samples (Total Tested=720) and Model-Adjusted Mean Prevalence, AND THEIR CORRESPONDING 95\% CONFIDENCE InTERVALS, OF Shiga TOXIN-Producing ESCHERICHIA COLI SEROGROUPS

\begin{tabular}{lrc}
\hline $\begin{array}{l}\text { STEC } \\
\text { serogroup }\end{array}$ & $\begin{array}{c}\text { Positives, } \\
\mathrm{n}(\%)\end{array}$ & $\begin{array}{c}\text { Model-adjusted mean prevalence* } \\
\text { in } \%(95 \% \text { CI })\end{array}$ \\
\hline O26 & $12(1.7)$ & $0.3(0.0-2.3)$ \\
O45 & $3(0.4)$ & $0.1(0.0-8.5)$ \\
O103 & $21(2.9)$ & $0.2(0.0-2.0)$ \\
O111 & $0(0.0)$ & - \\
O121 & $0(0.0)$ & $0.1(0.0-8.5)$ \\
O145 & $3(0.4)$ & $3.1(0.6-15.2)$ \\
O157 & $78(10.8)$ &
\end{tabular}

*From intercept-only, multilevel logistic regression models. CI, confidence interval; STEC, Shiga toxin-producing E. coli.

intervals (CIs) were computed, and Bonferroni adjustments were used to correct $p$-values for multiple comparisons.

\section{Results}

\section{Prevalence of STEC and associated risk factors}

Of the 720 hide samples, 117 (16.3\%) tested positive for at least one of the STEC O serogroups. Overall number and percent of positive samples, as well as model-adjusted mean prevalence for each STEC serogroup, by season and by processing plant, are presented in Tables $1-3$. No hide samples tested positive for STEC O111 or O121. E. coli O157 was the most predominant STEC serogroup detected $(10.8 \%)$, followed by $\mathrm{O} 103(2.9 \%)$ and $\mathrm{O} 26(1.7 \%)$. Most of these STEC-positive samples also harbored the intimin (eae) gene (Supplementary Table S1).

Season was significantly associated with hide prevalence of STEC O103 $(p<0.01)$ and STEC O157 $(p<0.01)$ (Table 2). For STEC O103, the highest prevalence was detected in spring, followed by summer and fall (Table 2). For STEC O157, the highest prevalence was observed in summer, being $\sim 4.5$ times greater compared with the prevalence observed in the spring or fall season (Table 2 ). Hide prevalence of STEC O26 tended to vary by season $(p=0.07)$.

The prevalence of STEC O103 $(p=0.01)$ and 0157 $(p<0.01)$ varied significantly by processing plant (Table 3$)$. Plant was not significantly associated with prevalence of STEC O26 $(p=0.23)$.

The most common hide sample score $(47.8 \%)$ was 1 , followed by $38.6 \%$ of hides that were scored as 0 and $13.6 \%$ that were scored as 2 (Tables 4-6). The distribution of hide cleanliness scores by season and plant is presented in Tables 5 and 6 . In the unconditional analysis, the hide cleanliness score was not significantly associated $(p=0.13)$ with mean prevalence of STEC O103 (the confounding effect of season or processing plant could not be evaluated given the small sample size). In contrast, the cleanliness score was significantly associated with the prevalence of STEC O157 $(p<0.01)$ after controlling for the confounding effect of season $(p<0.01)$. Hides assigned a score of 1 or 2 had a significantly higher mean prevalence of STEC O157 (12.3\% and $11.6 \%$, respectively) compared with hides assigned a score of $0(4.9 \%)$, after controlling for season of sampling (Table 7).

Further analysis of our data indicated that the presence of STEC O26 and of STEC O103 was significantly associated with the mean prevalence of STEC O157 in hides (Supplementary Table S2).

\section{Concentration of STEC and associated risk factors}

None of the hide samples were enumerable for non-O157 STEC. However, for STEC O157, over the 3 seasons, there were 28 enumerable samples $(3.9 \% ; 28 / 720)$ (Table 8$)$.

Mean concentration of STEC O157 significantly varied by season $(p<0.01)$, with concentration being significantly higher in summer compared with fall $(p<0.01)$ and spring $(p=0.03)$. Mean concentration of STEC O157 significantly varied by plant $(p=0.02)$, being significantly higher in plant 1 compared with plant $2(p<0.01)$. Hide cleanliness scores were not significantly associated $(p=0.32)$ with mean concentration of STEC O157.

Table 2. Number and Percent of Test-Positive Samples and Model-Adjusted Mean Prevalence of Shiga Toxin-Producing Escherichia coli Serogroups on Cattle Hide Surface Samples, as Determined by Culture-Based Methods, by Sampling Season

\begin{tabular}{|c|c|c|c|c|c|c|}
\hline \multirow[b]{2}{*}{$\begin{array}{l}\text { STEC } \\
\text { serogroup }\end{array}$} & \multicolumn{2}{|r|}{ Summer 2015} & \multicolumn{2}{|r|}{ Fall 2015} & \multicolumn{2}{|r|}{ Spring 2016} \\
\hline & $\begin{array}{l}\text { Positives, } \\
\mathrm{n}(\%)\end{array}$ & $\begin{array}{c}\text { Model-adjusted mean } \\
\text { prevalence, \% (95\% CI) }\end{array}$ & $\begin{array}{l}\text { Positives, } \\
\mathrm{n}(\%)\end{array}$ & $\begin{array}{c}\text { Model-adjusted mean } \\
\text { prevalence, \% (95\% CI) }\end{array}$ & $\begin{array}{l}\text { Positives, } \\
\mathrm{n}(\%)\end{array}$ & $\begin{array}{c}\text { Model-adjusted mean } \\
\text { prevalence, \% (95\% CI) }\end{array}$ \\
\hline $\mathrm{O} 26$ & $2(0.8)$ & $0.4(0.1-2.5)$ & $2(0.8)$ & $0.4(0.1-2.5)$ & $8(3.3)$ & $1.9(0.5-6.2)$ \\
\hline $\mathrm{O} 45$ & $1(0.4)$ & - & $2(0.8)$ & - & $0(0.0)$ & - \\
\hline O $103 *$ & $4(1.7)$ & $0.2^{\mathrm{a}}(0.0-2.1)$ & $2(0.8)$ & $0.1^{\mathrm{a}}(0.0-1.2)$ & $15(6.3)$ & $1.2^{\mathrm{b}}(0.2-8.0)$ \\
\hline O111 & $0(0.0)$ & - & $0(0.0)$ & - & $0(0.0)$ & - \\
\hline O121 & $0(0.0)$ & - & $0(0.0)$ & - & $0(0.0)$ & - \\
\hline $\mathrm{O} 145$ & $1(0.4)$ & - & $2(0.8)$ & - & $0(0.0)$ & - \\
\hline O157* & $52(21.7)$ & $18.2^{\mathrm{a}}(9.1-33.2)$ & $12(5.0)$ & $3.6^{\mathrm{b}}(1.4-8.9)$ & $14(5.8)$ & $4.2^{\mathrm{b}}(1.7-10.1)$ \\
\hline
\end{tabular}

240 Hide-on samples were collected in each season for a total of 720 samples.

*Indicates that STEC prevalence varied significantly $(p<0.05)$ by season.

${ }^{\mathrm{a}, \mathrm{b}}$ Different superscripts indicate a significant difference between model-adjusted mean prevalence between seasons within the STEC serogroup. 
Table 3. Number and Percent of Test-Positive Samples and Model-Adjusted Mean Prevalence of Shiga Toxin-Producing Escherichia coli Serogroups on Cattle Hide Surface Samples, as Determined by Culture-Based Methods, by Processing Plant

\begin{tabular}{|c|c|c|c|c|c|c|c|c|}
\hline \multirow[b]{2}{*}{$\begin{array}{l}\text { STEC } \\
\text { Serogroup }\end{array}$} & \multicolumn{2}{|c|}{ Plant 1} & \multicolumn{3}{|c|}{ Plant 2} & \multicolumn{2}{|c|}{ Plant 3} & \multirow{2}{*}{$\begin{array}{c}\text { Plant } 4 \\
\text { Model-adjusted } \\
\text { mean } \\
\text { prevalence, } \\
\%(95 \% C I)\end{array}$} \\
\hline & $\begin{array}{c}\text { Positives, } \\
\text { n (\%) }\end{array}$ & $\begin{array}{c}\text { Model-adjusted } \\
\text { mean } \\
\text { prevalence, } \\
\%(95 \% \text { CI })\end{array}$ & $\begin{array}{c}\text { Positives, } \\
\mathrm{n}(\%)\end{array}$ & $\begin{array}{c}\text { Model-adjusted } \\
\text { mean } \\
\text { prevalence, } \\
\%(95 \% \text { CI })\end{array}$ & $\begin{array}{c}\text { Positives, } \\
\mathrm{n}(\%)\end{array}$ & $\begin{array}{c}\text { Model-adjusted } \\
\text { mean } \\
\text { prevalence, } \\
\%(95 \% \text { CI })\end{array}$ & $\begin{array}{l}\text { Positives, } \\
\mathrm{n}(\%)\end{array}$ & \\
\hline $\mathrm{O} 26$ & $1(0.6)$ & $0.0(0.0-1.9)$ & $6(3.3)$ & $0.3(0.0-7.5)$ & $2(1.1)$ & $0.4(0.0-4.0)$ & $3(1.7)$ & $0.6(0.1-5.2)$ \\
\hline $\mathrm{O} 45$ & $0(0.0)$ & - & $1(0.6)$ & - & $2(1.1)$ & - & $0(0.0)$ & - \\
\hline O103* & $1(0.6)$ & $0.1^{\mathrm{a}}(0.0-0.9)$ & $14(7.8)$ & $1.3^{\mathrm{b}}(0.2-9.8)$ & $5(2.8)$ & $1.1^{\mathrm{a}, \mathrm{b}}(0.2-6.8)$ & $1(0.6)$ & $0.2^{\mathrm{a}, \mathrm{b}}(0.0-2.7)$ \\
\hline $\mathrm{O} 111$ & $0(0.0)$ & - & $0(0.0)$ & - & $0(0.0)$ & - & $0(0.0)$ & - \\
\hline O121 & $0(0.0)$ & - & $0(0.0)$ & - & $0(0.0)$ & - & $0(0.0)$ & - \\
\hline $\mathrm{O} 145$ & $0(0.0)$ & - & $0(0.0)$ & - & $2(1.1)$ & - & $1(0.6)$ & - \\
\hline O157* & $11(6.1)$ & $3.0^{\mathrm{a}}(0.5-15.0)$ & $31(17.2)$ & $\begin{array}{c}10.1^{\mathrm{b}}(2.1- \\
37.6)\end{array}$ & $7(3.9)$ & $1.0^{\mathrm{a}}(0.2-6.7)$ & $29(16.1)$ & $6.4^{\mathrm{a}}(1.1-28.8)$ \\
\hline
\end{tabular}

180 Samples were collected from each plant for a total of 720 samples.

*Indicates that STEC prevalence varied significantly $(p<0.05)$ by processing plant.

${ }^{\mathrm{a}, \mathrm{b}}$ Different superscripts indicate a significant difference between model-adjusted mean prevalence between plants within the STEC serogroup.

\section{Discussion}

Season (summer), processing plant, $>10 \%$ of hide surface covered in mud or feces, and the presence of STEC O103 or STEC 26 on hide samples were significantly associated with higher hide-on prevalence of STEC O157, the predominant serogroup in this study. Similarly, a subset ( $\sim 4 \%$ ) of samples was enumerable for STEC O157, with concentration differing by plant and season of sampling. Within non-O157 groups, although at low prevalence, STEC O103 and O26 were the most commonly detected, with $\mathrm{O} 103$ also significantly varying by season (spring) and by plant.

Hides are an important source of fecal bacterial contamination of carcasses during cattle processing (Reid et al., 2002; Barkocy-Gallagher et al., 2003; Nou et al., 2003; Bosilevac et al., 2005). Monitoring the prevalence and concentration of STEC on hides and throughout the slaughter process is critical to assess the efficacy of in-plant interventions for controlling STEC and other foodborne pathogens (Arthur et al., 2004; USDA-FSIS, 2017). Arthur et al. (2009) reported an association between fecal shedding in cattle and contamination of hides, suggesting that a reduction of $E$. coli

Table 4. Number and Percentage of Test-Positive SAMPles for EACH Shiga Toxin-Producing ESCHERICHIA COLI O GROUP BY HIDE Cleanliness Score

\begin{tabular}{lccc}
\hline & \multicolumn{3}{c}{ Hide cleanliness score } \\
\cline { 2 - 4 } STEC serogroup & 0 & 1 & 2 \\
\hline O26 & $\mathrm{n}(\%)$ & $\mathrm{n}(\%)$ & $\mathrm{n}(\%)$ \\
O45 & $0(0.0)$ & $10(83.3)$ & $2(16.7)$ \\
O103 & $0(0.0)$ & $1(33.3)$ & $2(66.7)$ \\
O111 & $5(23.8)$ & $13(61.9)$ & $3(14.3)$ \\
O121 & $0(0.0)$ & $0(0.0)$ & $0(0.0)$ \\
O145 & $0(0.0)$ & $0(0.0)$ & $0(0.0)$ \\
O157 & $1(33.3)$ & $1(33.3)$ & $1(33.3)$ \\
\hline
\end{tabular}

prevalence in feces and a reduction of the levels of shedding below a certain threshold (200 CFU/g) were important to prevent and control cross-contamination of hides.

In the present study, cumulative model-adjusted prevalence of STEC non-O157 and O157 on beef cattle hides was lower than previously reported, ranging from $0.1 \%$ for $\mathrm{O} 45$ and $\mathrm{O} 145$ and $0.2 \%$ for $\mathrm{O} 103$ to $0.3 \%$ for $\mathrm{O} 26$ and $3.1 \%$ for O157. Using similar culture procedures for isolation of STEC non-O157, Stromberg et al. (2015) and Noll et al. (2018) also found very low prevalence (0 to $6.8 \%$ ) of all STEC-7 serogroups on hides of fed cattle. Potential reasons for the low prevalence of STEC non-O157 on hides include potential misclassification of test results based on the sensitivity of the sampling procedures and diagnostic tests used as well as the effectiveness of hide interventions employed at the processing plant. Epidemiological studies play a significant role in the assessment of risks and risk factors associated with environmental pathogens and for informing regulatory standards and policy. Specifically, consistency of findings across studies is central for accurate estimation, evaluating the body of evidence, informing risk assessment, and supporting causal inference. Although limited, data on prevalence and risk factors for STEC serogroups on hides in beef processing plants are highly heterogeneous, with prevalence estimates ranging from $0 \%$ (by culture-dependent methods) to $74.5 \%$ for STEC non-O157 (by the culture-independent NeoSEEK ${ }^{\circledR}$

Table 5. Distribution of Hide Cleanliness SCORES BY SEASON

\begin{tabular}{lccc}
\hline & \multicolumn{3}{c}{ Hide cleanliness score } \\
\cline { 2 - 4 } Season & $\begin{array}{c}0 \\
\mathrm{n}(\%)\end{array}$ & $\mathrm{n}(\%)$ & $\mathrm{n}(\%)$ \\
\hline Summer & $97(40.4)$ & $106(44.2)$ & $37(15.4)$ \\
Fall & $100(41.7)$ & $109(45.4)$ & $31(12.9)$ \\
Spring & $81(33.8)$ & $129(53.8)$ & $30(12.5)$ \\
Total & $278(38.6)$ & $344(47.8)$ & $98(13.6)$ \\
\hline
\end{tabular}


Table 6. Distribution of Hide Cleanliness Scores by Processing Plant

\begin{tabular}{lccc}
\hline & \multicolumn{3}{c}{ Hide cleanliness score } \\
\cline { 2 - 4 } Plant & 0 & 1 & 2 \\
& $\mathrm{n}(\%)$ & $\mathrm{n}(\%)$ & $\mathrm{n}(\%)$ \\
\hline 1 & $82(45.6)$ & $93(51.7)$ & $5(2.8)$ \\
2 & $47(26.1)$ & $119(66.1)$ & $14(7.8)$ \\
3 & $100(55.6)$ & $48(26.7)$ & $32(17.8)$ \\
4 & $49(27.2)$ & $84(46.7)$ & $47(26.1)$ \\
Total & $278(38.6)$ & $344(47.8)$ & $98(13.6)$ \\
\hline
\end{tabular}

method) (Stromberg et al., 2015, 2016; Noll et al., 2018; Schneider et al., 2018) and a pooled prevalence estimate of $56.4 \%$ for STEC O157 (95\% CI: 48.6-64.1\%; obtained from 16 publications) (Ekong et al., 2015). Differences in factors such as management practices, diet and animal type, laboratory methodologies, sampling period, study design, geographical location, and plant interventions may explain the observed heterogeneity and discrepancies between the results reported in other studies and the data presented in the current study.

Fecal shedding of STEC in cattle, specifically of O157, has been linked to warmer months (Hussein, 2007; Williams et al., 2010; Lal et al., 2012; Ekong et al., 2015). The length of daylight and temperature have been suggested as possible factors associated with the growth and survival of E. coli in the cattle environment, which could explain increased exposure, and therefore shedding, in cattle (McClure and Hall, 2000; Edrington et al., 2006; Ekong et al., 2015). Other studies point to no association or association between seasons other than summer with higher STEC prevalence on hides. Brichta-Harhay et al. (2008) reported no significant associ-
Table 8. Mean Concentration of Shiga ToXin-Producing EsCherichia COLI O157 AMONG Enumerable Samples $(N=28)$ by Season, Plant, and Hide Cleanliness Score

\begin{tabular}{lrc}
\hline & & $\begin{array}{c}\text { Mean concentration, }{ }^{*} \log _{10} \\
\text { CFU/100 } \mathrm{cm}^{2}(\text { SD; range })^{\mathrm{a}, \mathrm{b}}\end{array}$ \\
\hline Season & $\mathrm{N}$ & \\
$\quad$ Summer & 16 & $2.6(0.6 ; 1.5-3.7)^{\mathrm{a}}$ \\
$\quad$ Fall & 8 & $1.6(0.4 ; 1.1-2.4)^{\mathrm{b}}$ \\
$\quad$ Spring & 4 & $1.6(0.2 ; 1.4-1.8)^{\mathrm{b}}$ \\
Plant & & \\
$\quad$ Plant 1 & 8 & $2.4(1.0 ; 1.4-3.7)^{\mathrm{a}}$ \\
Plant 2 & 8 & $1.6(0.4 ; 1.1-2.1)^{\mathrm{b}}$ \\
Plant 3 & 4 & $2.3(0.4 ; 1.8-2.7)^{\mathrm{a}}$ \\
Plant 4 & 8 & $2.3(0.7 ; 1.4-3.1)^{\mathrm{a}}$ \\
Hide cleanliness score & \\
$\quad$ Score 0 & 7 & $2.2(0.9 ; 1.1-3.7)$ \\
$\quad$ Score 1 & 6 & $2.1(0.6 ; 1.4-3.1)$ \\
$\quad$ Score 2 & 3 & $2.0(0.6 ; 1.4-2.7)$ \\
Total positive & $28($ of 720) & $2.1(0.7 ; 1.1-3.7)$ \\
\hline
\end{tabular}

*Among enumerable samples.

${ }^{\dagger} 12$ Samples were not assigned a hide score.

${ }^{\mathrm{a}, \mathrm{b}}$ Different superscripts indicate a significant difference between model-adjusted mean concentration of STEC O157 and each variable $(p<0.05)$.

$\mathrm{CFU}$, colony-forming unit; $n$, number of enumerable samples; $\mathrm{SD}$, standard deviation.

ation between season and prevalence, whereas Schneider et al. (2018) reported higher prevalence of enterohemorrhagic E. coli (EHEC) O145 on hides of cattle during winter, $\mathrm{O} 26$ during fall, and $\mathrm{O} 103$ and $\mathrm{O} 121$ during spring. In the present study, among non-O157 STEC, only the prevalence of STEC O103 significantly varied by season, peaking during

Table 7. Associations of Hide Cleanliness Scores and Season with Mean Prevalence of Shiga ToXin-Producing EsCHERICHIA COLI O157 ON HIDES

\begin{tabular}{|c|c|c|c|c|}
\hline Variable & $\mathrm{n}$ & $\begin{array}{l}\text { Positives, } \\
\text { n (\%) }\end{array}$ & $\begin{array}{c}\text { Model-adjusted mean } \\
\text { prevalence, \% (95\% CI) }\end{array}$ & $\mathrm{p}^{*}$ \\
\hline Hide cleanliness score & & & & $<0.01$ \\
\hline $0(<10 \%$ covered in mud or feces $)$ & 278 & $20(7.2)$ & $4.9(0.5-9.3)$ & \\
\hline 1 (10-30\% covered in mud or feces) & 344 & $44(12.8)$ & $12.3(3.8-20.9)$ & \\
\hline 2 ( $>30 \%$ covered in mud or feces) & 98 & $14(14.3)$ & $11.6(0.6-22.5)$ & \\
\hline \multirow[t]{5}{*}{ Total } & 720 & $78(10.8)$ & - & \\
\hline & & & \multicolumn{2}{|l|}{ Contrasts ${ }^{\dagger}$} \\
\hline & & & 1 vs. 0 & $<0.01$ \\
\hline & & & 2 vs. 0 & 0.04 \\
\hline & & & 1 vs. 2 & 0.85 \\
\hline Season & & & & $<0.01$ \\
\hline Summer & 240 & $52(21.7)$ & $20.5(6.9-34.1)$ & \\
\hline Fall & 240 & $12(5.0)$ & $3.4(0.1-6.8)$ & \\
\hline Spring & 240 & $14(5.8)$ & $4.2(0.0-8.3)$ & \\
\hline \multirow[t]{5}{*}{ Total } & 720 & $78(10.8)$ & & \\
\hline & & & \multicolumn{2}{|l|}{ Contrasts $^{\dagger}$} \\
\hline & & & Summer vs. Fall & $<0.01$ \\
\hline & & & Summer vs. Spring & $<0.01$ \\
\hline & & & Spring vs. Fall & 0.60 \\
\hline
\end{tabular}

From the multivariable model estimating associations of hide cleanliness scores and season with prevalence of STEC O157, accounting for plant and week of sampling as random intercepts.

*Overall $p$-value (Wald chi-square test).

${ }^{\dagger} p$-Values adjusted for multiple comparisons (Bonferroni). 
spring months. In a previous study, O103 was the most prevalent STEC serogroup isolated in feces of preslaughter feedlot cattle during summer months. Notably, the O103 serogroup, without Shiga toxin or intimin genes, was also detected in individual fecal samples $(41 \%)$ and in all study pens (17-92\%) during the winter months (Dewsbury et al., 2015). Whether the O103 serogroup can survive tougher environmental conditions such as the ones observed in winter or spring months, or displace other organisms and potentially acquire virulence genes, is not known and warrants further investigation. Collecting information on weather variables such as rainfall and temperature may provide additional metrics for predicting spikes in shedding, prompting the application of additional mitigation steps.

In certain seasons, when husbandry practices and environmental factors differ and are favorable for bacterial growth or survival, cattle may have higher mud scores than in other seasons. In previous studies, and likely because animals included are from different production systems, an association between hide cleanliness scores and prevalence of pathogenic bacteria has not been consistently reported (van Donkersgoed et al., 1997; Brown, 2000; Keen and Elder, 2002; Smith et al., 2005; Nastasijevic et al., 2007; Antic et al., 2010; Blagojevic et al., 2012; Schneider et al., 2018). In this study, we found that after accounting for season, hides with scores 1 and 2 were associated with significantly higher prevalence of STEC O157 than hides with score 0. Although subjective in nature, hide cleanliness scores (contamination metric) can be taken into account when considering modifying or supplementing production processes (USDA-FSIS, 2017). Among the plants evaluated in this study, the implementation and frequency of application of interventions depended upon the plants' management practices as well as the season, with additional interventions (i.e., spraying bacteriophage targeting $E$. coli in holding pens and rinsing hides with high-pressure water upon entry to the processing facility and after knocking) being more likely to be employed during warmer months (March to October). Although we could not concurrently test the association of season and plant (via an interaction term) with prevalence of STEC serogroups due to the small number of positives obtained, the prevalence of STEC $\mathrm{O} 157$ and $\mathrm{O} 103$ on hides did significantly vary by processing plant, which may be related to differences in plant management (e.g., infrastructure, standard operating procedures, hygiene, employee practices, and interventions) as well as the region of origin of beef cattle (representing differences in husbandry practices and diet, among others).

The nondetection of enumerable (concentration testing) samples for STEC non-O157 is probably due to low prevalence, below the detection limit of the procedure. On the contrary, and in accordance with results of previous studies, we did quantify STEC O157, with the highest concentration being observed during the summer sampling (BarkocyGallagher et al., 2003; Schneider et al., 2018).

\section{Conclusions}

This study points to a higher hide-on prevalence of STEC O157 in summer and of STEC non-O157 (specifically of STEC O103) in spring months. It is important, however, to note that none of the hide samples were enumerable for nonO157 STEC. Across seasons and plants, the presence of the most common STEC non-O157 serogroups in this study (O26 and O103) was associated with a higher prevalence of STEC O157. Given the challenges of sampling, testing, and monitoring non-O157 STEC on hides within plants, preharvest interventions targeting reduction of $\mathrm{O} 157$ on hides could be useful in reducing overall STEC contamination pressure at the plant. Nonetheless, plants could benefit from extending the application of interventions against STEC beyond summer and into fall and spring months when hide-on prevalence of STEC non-O157 is higher.

\section{Acknowledgments}

The authors thank STEC Coordinated Agricultural Program (CAP) interns (Hannah Seger, Justin Ludwig, Christine Bartley, and Carlee Wollard), veterinary research scholar program (VRSP) students (John Brandsma and Austin Pauly), student workers (Antoinette Lona, Alison Cioffi, and Amanda Katherns), graduate students (Charley Cull and Aurelio Cabezas), Dr. Christy Hanthorn, and laboratory technicians (Xiaorong Shi, Neil Wallace, and Leigh Ann Feuerbacher) for their help and technical assistance. The authors also thank collaborators and students at West Texas A\&M University for assisting with the sample collection and processing plants for allowing them to collect samples at their facilities.

\section{Disclosure Statement}

The authors declare no conflicts of interest.

\section{Funding Information}

This research was supported by the Agriculture and Food Research Initiative STEC CAP Grant (number 2012-6800330155) from the United States Department of Agriculture National Institute of Food and Agriculture (USDA NIFA) and the College of Veterinary Medicine at Kansas State University.

\section{Supplementary Material}

Supplementary Table S1

Supplementary Table S2

\section{References}

Antic D, Blagojevic B, Ducic M, Nastasijevic I, Mitrovic R, Buncic S. Distribution of microflora on cattle hides and its transmission to meat via direct contact. Food Control 2010; 21:1025-1029.

Arthur TM, Bosilevac JM, Nou X, Shackelford SD, Wheeler TL, Kent MP, Jaroni D, Pauling B, Allen DM, Koohmaraie M. Escherichia coli 0157 prevalence and enumeration of aerobic bacteria, Enterobacteriaceae, and Escherichia coli O157 at various steps in commercial beef processing plants. J Food Prot 2004;67:658-665.

Arthur TM, Keen JE, Bosilevac JM, Brichta-Harhay DM, Kalchayanand N, Shackelford SD, Wheeler TL, Nou X, Koohmaraie M. Longitudinal study of Escherichia coli O157: $\mathrm{H} 7$ in a beef cattle feedlot and role of high-level shedders in hide contamination. Appl Environ Microbiol 2009;75:65156523.

Bai J, Paddock ZD, Shi X, Li S, An B, Nagaraja TG. Applicability of a multiplex PCR to detect the seven major Shiga 
toxin-producing Escherichia coli based on genes that code for serogroup-specific $\mathrm{O}$-antigens and major virulence factors in cattle feces. Foodborne Pathog Dis 2012;9:541-548.

Bai J, Shi X, Nagaraja TG. A multiplex PCR procedure for the detection of six major virulence genes in Escherichia coli O157:H7. J Microbiol Methods 2010;82:85-89.

Barkocy-Gallagher GA, Arthur TM, Rivera-Betancourt M, Nou X, Shackelford SD, Wheeler TL, Koohmaraie M. Seasonal prevalence of Shiga toxin-producing Escherichia coli, including O157:H7 and non-O157 serotypes, and Salmonella in commercial beef processing plants. J Food Prot 2003;66: 1978-1986.

Bettelheim KA. Role of non-O157 VTEC. J Appl Microbiol 2000;88:38S-50S.

Blagojevic B, Antic D, Ducic M, Buncic S. Visual cleanliness scores of cattle at slaughter and microbial loads on the hides and the carcasses. Vet Rec 2012;170:563-570.

Bosilevac JM, Nou X, Osborn MS, Allen DM, Koohmaraie M. Development and evaluation of an on-line hide decontamination procedure for use in a commercial beef processing plant. J Food Prot 2005;68:265-272.

Brichta-Harhay DM, Guerini MN, Arthur TM, Bosilevac JM, Kalchayanand N, Shackelford SD, Wheeler TL, Koohmaraie M. Salmonella and Escherichia coli O157:H7 contamination on hides and carcasses of cull cattle presented for slaughter in the United States: An evaluation of prevalence and bacterial loads by immunomagnetic separation and direct plating methods. Appl Environ Microbiol 2008;74:6289-6297.

Brooks JT, Sowers EG, Wells JG, Greene KD, Griffin PM, Hoekstra RM, Strockbine NA. Non-O157 Shiga toxin-producing Escherichia coli infections in the United States, 19832002. J Infect Dis 2005;192:1422-1429.

Brown M. HACCP in the Meat Industry. 1st ed. Southampton: Woodhead Publishing, 2000.

Caprioli A, Morabito S, Brugere H, Oswald E. Enterohaemorrhagic Escherichia coli: Emerging issues on virulence and modes of transmission. Vet Res 2005;36:289-311.

Cernicchiaro N, Oliveira ARS, Hoehn A, Cull CA, Noll LW, Shridhar PB, Nagaraja TG, Ives SE, Renter DG, Sanderson MW. Quantification of bacteria indicative of fecal and environmental contamination from hides to carcasses. Foodborne Pathog Dis 2019;16:844-855.

Dewsbury DM, Renter DG, Shridhar PB, Noll LW, Shi X, Nagaraja TG, Cernicchiaro N. Summer and winter prevalence of Shiga toxin-producing Escherichia coli (STEC) O26, O45, O103, O111, O121, O145 and O157 in feces of feedlot cattle. Foodborne Pathog Dis 2015;12:726-732.

Edrington TS, Callaway TR, Ives SE, Engler MJ, Looper ML, Anderson RC, Nisbet DJ. Seasonal shedding of Escherichia coli $\mathrm{O} 157: \mathrm{H} 7$ in ruminants: A new hypothesis. Foodborne Pathog Dis 2006;3:413-421.

Ekong PS, Sanderson MW, Cernicchiaro N. Prevalence and concentration of Escherichia coli O157 in different seasons and cattle types processed in North America: A systematic review and meta-analysis of published research. Prev Vet Med 2015;121:74-85.

Elder RO, Keen JE, Siragusa GR, Barkocy-Gallagher GA, Koohmaraie M, Laegreid WW. Correlation of enterohemorrhagic Escherichia coli $\mathrm{O} 157$ prevalence in feces, hides, and carcasses of beef cattle during processing. Proc Natl Acad Sci U S A 2000;97:2999-3003.

Gilchrist JE, Campbell JE, Donnelly CB, Peeler JT, Delaney JM. Spiral plate method for bacterial determination. Appl Microbiol 1973;25:244-252.
Hauge SJ, Hafstad O, Røtterud O, Nesbakken T. The hygienic impact of categorization of cattle by hide cleanliness in the abattoir. Food Control 2012;27:100-107.

Hussein HS. Prevalence and pathogenicity of Shiga toxinproducing Escherichia coli in beef cattle and their products. J Anim Sci 2007;85:E63-E72.

IUL, S.A. Eddy Jet 2 user's guide V. 1.0. Barcelona, Spain. 2012. Available at: www.revodix.co.kr/wp-content/uploads/ 2015/08/Eddy-Jet2-\%EC\%82\%AC\%EC\%9A\%A9\%EC\%84 $\%$ A4\%EB\%AA\%85\%EC\%84\%9C.pdf (accessed December 1, 2019).

Keen JE, Elder RO. Isolation of Shiga-toxigenic Escherichia coli $\mathrm{O} 157$ from hide surfaces and the oral cavity of finished beef feedlot cattle. J Am Vet Med Assoc 2002;220:756-763.

Lal A, Hales S, French N, Baker MG. Seasonality in human zoonotic enteric diseases: A systematic review. PLoS One 2012;7:e31883.

McClure PJ, Hall S. Survival of Escherichia coli in foods. J Appl Microbiol 2000;88:618-708.

Nastasijevic I, Mitrovic R, Buncic S. Occurrence of Escherichia coli $\mathrm{O} 157$ on hides of slaughtered cattle. Lett Appl Microbiol 2007;46:126-131.

Noll LW, Baumgartner WC, Shridhar PB, Cull CA, Dewsbury DA, Shi X, Cernicchiaro N, Renter DG, Nagaraja TG. Pooling of immunomagnetic separation beads does not affect detection sensitivity of six major serogroups of Shiga toxinproducing Escherichia coli in cattle feces. J Food Prot 2016; 79:59-65.

Noll LW, Shridhar PB, Dewsbury DM, Shi X, Cernicchiaro N, Renter DG, Nagaraja TG. A comparison of culture- and PCRbased methods to detect six major non-O157 serogroups of Shiga toxin-producing Escherichia coli in cattle feces. PLoS One 2015;10:1371-1382.

Noll LW, Shridhar PB, Ives SE, Cha E, Nagaraja TG, Renter DG. Detection and quantification of seven major serogroups of Shiga toxin-producing Escherichia coli on hides of cull dairy, cull beef and fed beef cattle at slaughter. J Food Prot 2018;81:1236-1244.

Nou X, Rivera-Betancourt M, Bosilevac JM, Wheeler TL, Shackelford SD, Gwartney BL, Reagan JO, Koohmaraie M. Effect of chemical dehairing on the prevalence of Escherichia coli $\mathrm{O} 157: \mathrm{H} 7$ and the levels of aerobic bacteria and Enterobacteriaceae on carcasses in a commercial beef processing plant. J Food Prot 2003;66:2005-2009.

Pennington H. Escherichia coli O157. Lancet 2010;376:14281435.

Reid CA, Small A, Avery SM, Buncic S. Presence of foodborne pathogens on cattle hides. Food Control 2002;13:411415.

Scallan E, Hoekstra RM, Angulo FJ, Tauxe RV, Widdowson MA, Roy SL, Jones JL, Griffin PM. Foodborne illness acquired in the United States-major pathogens. Emerg Infect Dis 2011;17:7-15.

Schneider LG, Stromberg ZR, Lewis GL, Moxley RA, Smith DR. Cross-sectional study to estimate the prevalence of enterohaemorrhagic Escherichia coli on hides of market beef cows at harvest. Zoonoses Public Health 2018;65:625636.

Shridhar PB, Noll LW, Cull CA, Shi X, Cernicchiaro N, Renter DG, Bai J, Nagaraja TG. Spiral plating method to quantify the six major non-O157 Escherichia coli serogroups in cattle feces. J Food Prot 2017;80:848-856.

Smith DR, Moxley RA, Clowser SL, Folmer JD, Hinkley S, Erickson GE, Klopfenstein TJ. Use of rope devices to de- 
scribe and explain the feedlot ecology of Escherichia coli O157:H7 by time and place. Foodborne Pathog Dis 2005;2: 50-60.

Stromberg ZR, Baumann NW, Lewis GL, Sevart NJ, Cernicchiaro N, Renter DG, Marx DB, Phebus RK, Moxley RA. Prevalence of enterohemorrhagic Escherichia coli O26, O45, O103, O111, O121, O145, and O157 on hides and preintervention carcass surfaces of feedlot cattle at harvest. Foodborne Pathog Dis 2015;12:631-638.

Stromberg ZR, Lewis GL, Aly SS, Lehenbauer TW, Bosilevac JM, Cernicchiaro N, Moxley RA. Prevalence and level of enterohemorrhagic Escherichia coli in culled dairy cows at harvest. J Food Prot 2016;79:421-431.

[USDA-FSIS] United States Department of Agriculture, Food Safety and Inspection Service. Rules and regulations. Shiga toxin-producing Escherichia coli in certain raw beef products. 2012. Available at: www.fsis.usda.gov/wps/wcm/connect/ 9c5840dd-c126-c4d79-983e-4b42cd794457/2010-0023FRN .pdf?MOD=AJPERES (accessed May 15, 2019).

[USDA-FSIS] United States Department of Agriculture, Food Safety and Inspection Service. FSIS Compliance guideline for minimizing the risk of Shiga toxin-producing Escherichia coli (STEC) and Salmonella in beef (including veal) slaughter operations. 2017. Available at: www.fsis.usda.gov/wps/wcm/ connect/1c7b15f7-2815-41d4-9897-2b0502d98429/ComplianceGuideline-STEC-Salmonella-Beef-Slaughter.pdf?MOD= AJPERES (accessed May 15, 2019).

[USDA-FSIS] United States Department of Agriculture, Food Safety and Inspection Service. FSIS Notice 50-05. Incident investigation team methodology for Escherichia coli (E. coli) O157:H7 in beef slaughter establishments. 2005. Available at: www.fsis.usda.gov/wps/wcm/connect/a5e3b125-ec50-54a28bd4f-8bf882362069/IIT_Methodology_for_Ecoli.pdf?MOD= AJPERES\&CACHEID=78354479-1 cc8-4d32-39fee-fb01 ba 929268 (accessed January 27, 2020).

van Donkersgoed J, Jericho KWF, Grogan H, Thorlakson B. Preslaughter hide status of cattle and the microbiology of carcasses. J Food Prot 1997;60:1502-1508.

Wheeler TL, Kalchayanand N, Bosilevac JM. Pre- and postharvest interventions to reduce pathogen contamination in the U.S. beef industry. Meat Sci 2014;98:372-382.

Williams MS, Withee JL, Ebel ED, Bauer NE, Scholosser WD, Disney WT, Smith DR, Moxley RA. Determining relationships between the seasonal occurrence of Escherichia coli O157:H7 in live cattle, ground beef and humans. Foodborne Pathog Dis 2010;7:1247-1254.

Address to:

Natalia Cernicchiaro, DVM, MS, PhD

Department of Diagnostic Medicine and Pathobiology

College of Veterinary Medicine

Kansas State University

332 Coles Hall, 1800 Denison Avenue

Manhattan, KS 66506

USA

E-mail: ncernic@vet.k-state.edu 